\title{
Revealing the Secrets of Strong Iron Enrichment in Hard Dental Tissues from Feral Coypu (Myocastor coypus) by Analytical (S)TEM
}

\author{
Vesna Srot $^{1}$, Ute Salzberger ${ }^{1}$, Birgit Bussmann ${ }^{1}$, Boštjan Pokorny ${ }^{2,3}$, Ida Jelenko ${ }^{2}$ and Peter A. van \\ Aken $^{1}$ \\ 1. Stuttgart Center for Electron Microscopy, Max Planck Institute for Intelligent Systems, Stuttgart, \\ Germany \\ 2. ERICo Velenje, Ecological Research and Industrial Cooperation, Velenje, Slovenia \\ 3. Environmental Protection College, Velenje, Slovenia
}

The diversity of biominerals produced by living organisms in respect of varying composition and structure is very remarkable. Many of these biominerals are highly complex composite materials with excellent physical and mechanical properties [1,2] which cannot be mimicked in laboratory. The combinations of organic matrix and amorphous and crystalline minerals formed under conditions of moderate temperature, pressure and $\mathrm{pH}$ possess masterpiece architectures with superior materials characteristics compared to geological counterparts or their synthetically made analogues [2,3].

Rodents possess opposing long pairs of continuously growing incisors that are worn down by gnawing. The front part of the incisors is enamel, which is the hardest tissue of the body containing $96 \mathrm{wt} \%$ of inorganic material; the inner part is softer dentine that forms the bulk of the teeth [4]. Surface of incisors of several different rodent species shows characteristic orange-brown colour and is identified with the presence of iron [5]. Based on electron microprobe characterization of the enamel surface layer [6] the amount of iron is $10-30 \mathrm{wt} \%$.

In the present study, upper and lower incisors of the feral coypu (Myocastor coypus Molina) were investigated. The microstructure and chemical composition at the enamel surface and in dentine were studied in detail by using energy-dispersive X-ray spectroscopy (EDX) and electron energy-loss spectroscopy (EELS) combined with scanning transmission electron microscopy (STEM) at high spatial resolution using a VG HB501UX and the Zeiss SESAM microscopes.

Our investigations uncovered the layer with a variable thickness, in some areas of up to $1 \mu \mathrm{m}$, present on the outer surface of the teeth which has not been observed before in rodent teeth. An annular dark field (ADF)-STEM image of a cross-sectional view showing the interface between the Fe-rich surface layer (Fe-SL) and Fe-rich enamel (Fe-E) is presented in Figure 1a. Fe- $\mathrm{L}_{2,3}$ energy-loss near-edge structures (ELNES) acquired from Fe-SL and Fe-E are presented in Figure $1 \mathrm{~b}$ and exhibit two main spin-orbit split $\mathrm{L}_{3}$ and $\mathrm{L}_{2}$ lines which are characteristic of the Fe valence state [7,8]. According to the $\mathrm{Fe}-\mathrm{L}_{2,3}$ ELNES fingerprints we conclude that $\mathrm{Fe}$ in $\mathrm{Fe}-\mathrm{SL}$ and in $\mathrm{Fe}-\mathrm{E}$ is present as predominantly $\mathrm{Fe}^{3+}$. Based on our EDX measurements (Figure 1c) the amount of Fe in the Fe-SL is much higher compared to the concentration values reported by now. In addition, the presence of minor amounts of sodium (Na), magnesium $(\mathrm{Mg})$ and potassium $(\mathrm{K})$ was noticed in the Fe-SL.

There is a wide occurrence of iron in many organisms; however the function of iron in hard dental tissues is not adequately understood. Present findings will promote the understanding of $\mathrm{Fe}$ incorporation in the enamel at the nanoscale level. 


\section{References:}

[1] UGK Wegst and MF Ashby, Philos Mag 84 (2004), 2167.

[2] AP Jackson and JFV Vincent, J Mater Sci 25 (1990), 3173.

[3] PUP Gilbert et al., Rev Mineral Geochem 59 (2005), 157.

[4] BA Niemec in "Small animal dental, oral \& maxillofacial disease" (2010), Manson Publishing Ltd, London.

[5] EV Pindborg JJ Pindborg and CM Plum, Acta Pharmacol 2 (1946), 294.

[6] A Halse, Archs Oral Biol 19 (1974), 7.

[7] LAJ Garvie, AJ Craven and R Brydson, Amer Mineral 79 (1994), 411.

[8] PA van Aken, B Liebscher and VJ Styrsa, Phys Chem Minerals 25 (1998), 323.
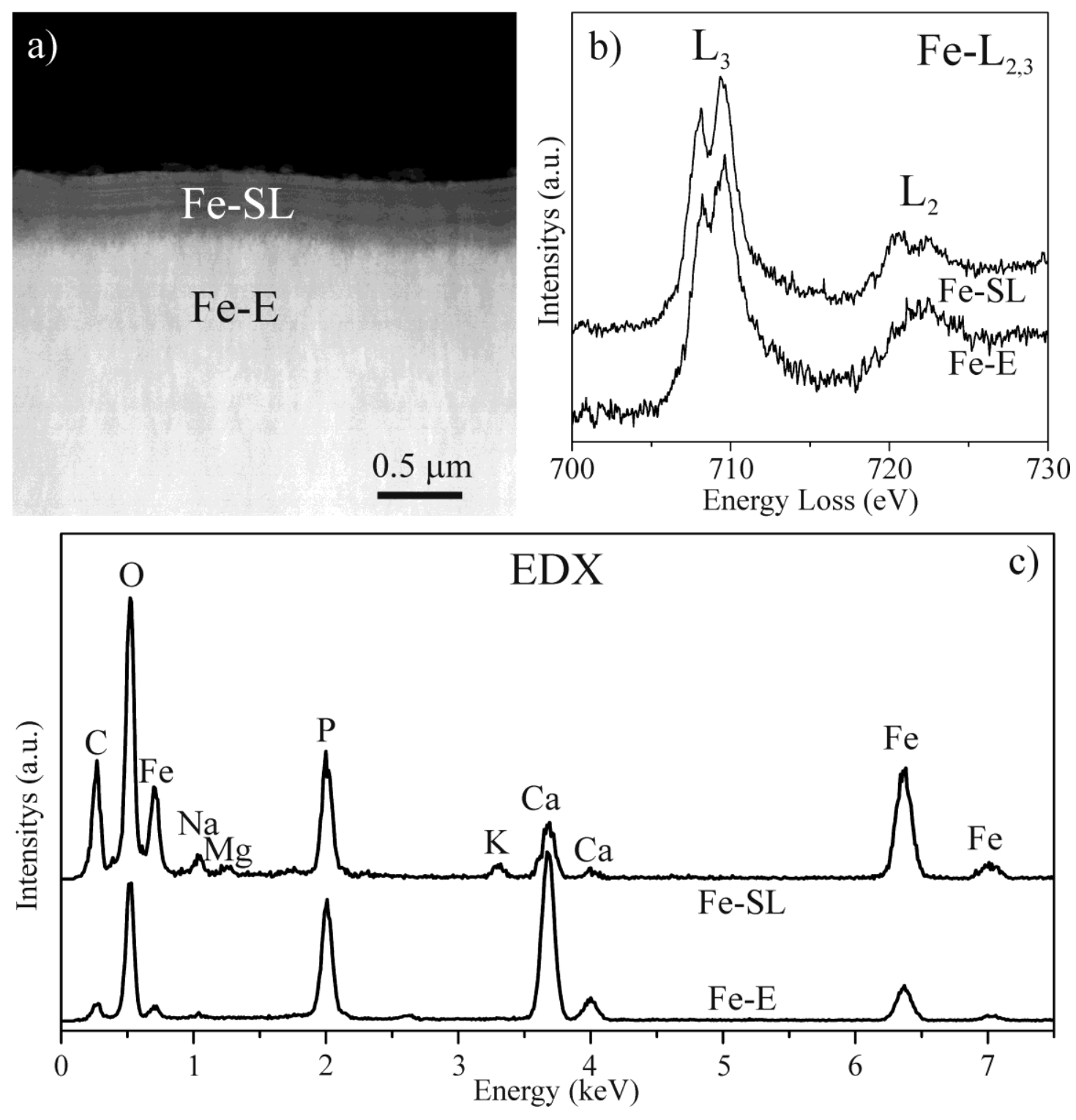

Figure 1. ADF-STEM image (a) of the interface between Fe-rich surface layer (Fe-SL) and the Fe-rich enamel (Fe-E) with (b) corresponding Fe- $\mathrm{L}_{2,3}$, ELNES and (c) EDX spectra. 